\title{
Competências em língua estrangeira para a produção e recepção de gêneros textuais em práticas laborais específicas
}

\author{
Renata Mourão Guimarães ${ }^{1}$
}

\begin{abstract}
RESUMO
Este trabalho tem como objetivo elucidar subsídios para o estabelecimento de competências em língua estrangeira (LE) requisitadas na produção e recepção de gêneros textuais que integram práticas laborais específicas, a partir de uma análise de necessidades da situação-alvo baseada nos estudos de sistema de gêneros de Bazerman (2005) e de comunidade discursiva de Swales (1990), visando à sistematização de aspectos relacionados ao ensino de LE no contexto da Educação Profissional e Tecnológica (EPT). Para tal, tomamos como exemplo os gêneros textuais comuns aos profissionais técnicos e tecnólogos do eixo Produção Alimentícia. Foi realizada uma pesquisa bibliográfica, seguida de uma coleta de informações com base documental no Catálogo Nacional de Cursos Técnicos (CNCT), no Catálogo Nacional de Cursos Superiores de Tecnologia (CNCST), bem como em ofertas públicas de emprego de alguns sites de empresas especializadas em recolocação profissional. Os resultados apontam na direção do delineamento de um syllabus, indicando os elementos que poderão ser trabalhados em LE em cursos voltados aos profissionais do eixo tecnológico Produção Alimentícia. Nesse sentido, foram apresentadas possíveis inter(ações) em LE da situação-alvo; contextos, situações comunicativas, pessoas e objetos envolvidos nas interações; habilidades linguísticas de compreensão/produção oral e escrita; elementos linguísticos-comunicativos, possibilitando estabelecer as competências (conhecimentos, habilidades, atitudes e valores) em LE necessárias para a produção e recepção dos gêneros textuais que circulam nas práticas produtivas do referido eixo.
\end{abstract}

PALAVRAS-CHAVE: Língua Estrangeira. Competências. Gêneros Textuais.

\section{RESUMEN}

Este trabajo tiene como objetivo elucidar subsidios para el establecimiento de competencias en lengua extranjera (LE) requisitadas para la producción y recepción de géneros textuales que integran prácticas laborales específicas, a partir de un análisis de necesidades de la situación meta basado en los estudios del sistema de género de Bazerman (2005) y de comunidad discursiva de Swales (1990), con el objetivo de sistematizar aspectos relacionados con la enseñanza de LE en el contexto de la Educación Profesional y Tecnológica (EPT). Para ello, tomamos como ejemplo los géneros textuales comunes a los profesionales técnicos y tecnólogos del eje Producción Alimentaria. Se realizó una investigación bibliográfica, seguida de una recopilación de información documental en el Catálogo Nacional de Cursos Técnicos (CNCT), en el Catálogo Nacional de Cursos Superiores de Tecnología (CNCST), así como en ofertas públicas de empleo de algunos sitios de empresas especializadas en el reemplazo profesional. Los resultados apuntan hacia el diseño de un sílabo, indicando los elementos que pueden ser trabajados en LE en cursos enfocados a los profesionales del eje de Producción de Alimentos. En este sentido, se presentaron inter(acciones) en LE que pueden llevar a cabo en la situación meta; contextos, situaciones comunicativas, personas y objetos involucrados en las interacciones; habilidades lingüisticas de comprensión/producción oral y escrita; elementos lingüísticoscomunicativos, posibilitando establecer las competencias en LE necesarias para la producción y recepción de los géneros textuales que circulan en las prácticas productivas de los profesionales de dicho eje tecnológico.

PALABRAS CLAVE: Lengua Extranjera. Competencia. Género Textuales.

\footnotetext{
${ }^{1}$ Mestra em Linguística Aplicada pela Universidade de Brasília (2015). Atualmente, cursa doutorado em Linguística pela mesma universidade. É professora do Instituto Federal de Brasília (IFB). E-mail: renata.guimaraes@ifb.edu.br
} 


\section{Introdução}

O contexto de formação profissional prevê o desenvolvimento de competências para o trabalho e para o exercício da cidadania. Competência é a "faculdade de mobilizar saberes, capacidades, informações para solucionar uma série de situações" (PERRENOUD, 1999, p. 30). No tocante às competências na perspectiva da laborabilidade, entendemos como "a capacidade de articular, mobilizar e colocar em ação valores, conhecimentos e habilidades necessárias para o desempenho eficiente e eficaz de atividades requeridas pela natureza do trabalho" (BRASIL, 1999, p.24), ou ainda, “como a capacidade pessoal de articular os saberes (saber, saber fazer, saber ser e conviver) inerentes a situações concretas de trabalho" (BRASIL, 1999, p.25).

Qquanto ao ensino de língua estrangeira (doravante LE) no contexto da Educação Profissional e Tecnológica (EPT), consideramos, portanto, o desenvolvimento de competências (conhecimentos, habilidades, atitudes e valores) necessárias para a inter(ação) por meio da linguagem em atividades laborais requeridas pela natureza de determinada área/eixo profissional.

Agimos e interagimos em práticas sociais por meio de gêneros. Os gêneros são, segundo Marcuschi (2005, p.9), "formas textuais típicas de cada atividade social", em outras palavras, formas de ação social e de materialização/organização linguística de eventos comunicativos concretos e específicos de determinada prática social. Segundo Barzeman (2005), para cada sistema de atividades humanas existe um conjunto de sistema de gêneros reconhecíveis pelos interagentes de uma "comunidade discursiva" (SWALES,1990).

Nesse sentido, este trabalho tem como propósito elucidar subsídios para 0 estabelecimento de competências em língua estrangeira requisitadas na produção e recepção de gêneros textuais que integram as práticas laborais comuns aos profissionais técnicos e tecnólogos do eixo Produção Alimentícia, a partir de uma análise de necessidades baseada nos estudos de sistema de gêneros de Bazerman (2005) e de comunidade discursiva de Swales (1990), visando à sistematização de aspectos relacionados ao ensino de LE no contexto da EPT. 
O levantamento de dados foi realizado a partir de informações do Catálogo Nacional de Cursos Técnicos (CNCT), do Catálogo Nacional de Cursos Superiores de Tecnologia (CNCST), bem como de ofertas públicas de emprego em alguns sites de empresas especializadas em recolocação profissional.

O fato deste estudo ressaltar as competências necessárias para a produção e recepção dos gêneros textuais que circulam nas práticas produtivas de um determinando eixo, e não apenas de uma área específica, deve-se ao intento de discutir formas de oportunizar aos alunos o aproveitamento contínuo e articulado dos estudos. Isso porque segundo o Decreto $n^{0} 8.268$, de 2014, as unidades curriculares de cursos e programas de EPT devem viabilizar aos alunos um aproveitamento articulado da aprendizagem $e$ continuidade da formação, tendo, assim, uma relação direta com a concepção de um perfil polivalente. A polivalência é entendida como atribuição que tem o profissional para superar “os limites de uma ocupação ou campo circunscrito de trabalho, para transitar para outros campos ou ocupações da mesma área profissional ou de áreas afins" (BRASIL, 1999, p. 37).

A EPT compreende uma série de processos educativos com natureza, duração e objetivos diferenciados (CHRISTOPHE, 2005), em uma ampla variedade de cursos de diferentes níveis e modalidades de ensino e em 13 eixos tecnológicos ${ }^{2}$. Mapear, portanto, as competências comuns aos profissionais de determinando eixo, possibilitaria 0 aproveitamento contínuo e articulado dos estudos por parte dos alunos e ao professor a possibilidade da organização curricular da LE a partir da construção de unidades curriculares flexíveis que tenham em sua estrutura práticas produtivas (laborais) comuns aos profissionais técnicos/tecnólogos de diferentes áreas dentro de um mesmo eixo e, logo, uma organização didático-pedagógica centrada no perfil do profissional polivalente.

Este estudo se justifica em virtude da necessidade de refletir sobre a organização de cursos de LE com conhecimentos que possam servir de instrumentos para a participação ativa dos alunos em atividades da vida real (nesse caso, vida profissional) e que permitam aos alunos superar os limites de sua área, bem como a transitar por áreas afins, atendendo aos propósitos de formação da EPT.

\footnotetext{
${ }^{2}$ Constam nos catálogos 13 eixos, os quais estão subdivididos em vários cursos, a saber: Ambiente e Saúde; Controle e Processos Industriais; Desenvolvimento Educacional e Social; Gestão e Negócios; Turismo, Hospitalidade e Lazer; Informação e Comunicação; Infraestrutura; Militar; Produção Alimentícia; Produção Cultural e Design; Produção Industrial; Recursos Naturais e Segurança.
} 


\section{LínguaTec}

\section{Pressupostos teóricos}

O aporte teórico constitui-se do diálogo entre a teoria de análise de necessidades (HUTCHINSON e WATERS, 1987; DUDLEY-EVANS e ST. JOHN, 1998; RAMOS, 2004, 2005; RAMOS et.al 2004; AUGUSTO-NAVARRO, 2008; AGUIRRE BELTRÁN, 2012) e a teoria de gêneros textuais, particularmente, nos estudos de sistema de gêneros de Bazerman (2005) e de comunidade discursiva de Swales (1990), apresentadas em textos das seções seguintes.

\subsection{Análise de necessidades}

Tratar do ensino de LE na EPT implica discutir o ensino de línguas para fins específicos (ELFE), nesse caso, o ensino de línguas para fins profissionais, fins ocupacionais, fins vocacionais, ou, ainda, formação para o trabalho. Em um planejamento de curso de ELFE, o procedimento de análise de necessidades (HUTCHINSON e WATERS, 1987; DUDLEY-EVANS e ST. JOHN, 1998; RAMOS, 2004, 2005; AUGUSTO-NAVARRO, 2008; AGUIRRE BELTRÁN, 2012) se torna imprescindível.

Para Hutchinson e Waters (1987), nessa análise, entra em discussão o que os alunos precisam aprender para atuar em determinada situação-alvo, o que querem aprender e o que precisam fazer para aprender. A análise de necessidades busca, dessa maneira, identificar as competências (de linguagem) necessárias para a inter(ação) dos alunos durante determinadas práticas sociais, sejam elas do âmbito profissional, acadêmico, pessoal ou público.

A análise de necessidades busca, assim, selecionar o que o aluno precisa saber/produzir em linguagem de determinado domínio discursivo para desenvolver-se eficazmente em uma situação comunicativa e/ou, ainda, o que querem aprender e o que precisam fazer para aprender. De acordo com Ramos (2004, 2005), essa análise visa reconhecer os tipos de discurso que os alunos têm de ser capazes de entender ou produzir na situação-alvo, trazendo ao professor subsídios para definir o que precisa ser ensinado e subsídios para a elaboração de um syllabus, que consiste, segundo Aguirre Beltrán (2012) na seleção, gradação e sequência dos conteúdos, isto é, organização dos temas, das 
habilidades, das funções comunicativas, dos itens gramaticais e lexicais entre outros elementos que serão trabalhados em uma unidade (HUTCHINSON e WATERS, 1987).

Segundo Dudley-Evans e St. John (1998), com base nas necessidades, torna-se possível: (a) elaborar um curso; (b) avaliar e/ou produzir um material didático; e, (c) definir processos de ensino-aprendizagem e de avaliação dos estudantes. Para Ramos et.al. (2004), a análise de necessidades deve servir para identificar os gêneros a serem explorados ao longo de um curso.

Considerando tal perspectiva, para a análise de necessidade, tomaremos por base 0 trabalho de Barzeman (2005) e de Swales (1990) que trazem contribuições para os estudos de gêneros relevantes para este trabalho.

\subsection{Gêneros textuais, sistema de gêneros e comunidade discursiva}

Swales (1990) define os gêneros como eventos comunicativos efetivados em uma comunidade discursiva, sob um determinado propósito, seguindo uma organização retórica que influencia escolhas léxico-gramaticais e de estruturação. Para esse autor, comunidade discursiva é compreendida como um grupo de indivíduos interactores que responde a vários critérios: ter: 1) um conjunto de objetivos detectáveis; 2) mecanismos de intercomunicação entre seus membros; 3) um conjunto de propósitos que move os mecanismos participatórios; 4) uma utilização seletiva e evoluinte desses mecanismos; 5) um léxico específico em desenvolvimento; 6) uma estrutura hierárquica explícita ou implícita que controla o processo de entrada na comunidade e a ascensão dentro dela. (SWALES, 199092 apud RAMOS, 2007, p. 185).

Para Bazerman (2005), todo gênero se inter-relaciona com outros, formando um conjunto de gêneros. Conjunto de gêneros é, portanto, um conjunto de textos adequados em determinada esfera social, que se vale para estabelecer a comunicação, com outras pessoas na mesma esfera (BAZERMAN, 2007 apud RAMOS 2005). Na esfera profissional, pessoas de uma mesma área acabam construindo diferentes conjuntos de gêneros que se interacionam dentro do chamado sistema de gêneros. Sistemas de gêneros são diversos conjuntos de gêneros que circulam entre pessoas - portanto, produzidos coletivamente. As pessoas participam da rede de práticas numa dada esfera social, como trabalho, por exemplo. "Os sistemas de gêneros capturam as sequências regulares com que o gênero 
segue um outro gênero, dentro de um fluxo comunicativo" (BAZERMAN, 2005 apud RAMOS, 2007, p.32).

Sendo assim, um conjunto de gêneros combinado em um sistema de gêneros possibilita identificar padrões que organizam o trabalho de uma determinada área profissional, caracterizando o seu sistema de atividades. Para Ramos (2007), há uma relação de pertencimento de determinados conjuntos de gêneros a determinado sistema de gêneros, uma vez que cada conjunto de produção pessoal está relacionado a outro ou a outro(s) conjunto(s), constituindo um complexo sistema. E isso determina o sistema de atividades humanas, em que todo ato é linguístico.

Bazerman (2005) apresenta métodos para analisar textos constituintes da própria atividade e organização de grupos sociais. Essa metodologia permite ao pesquisador mapear fatos sociais, atos de fala, gêneros, sistemas de gêneros e sistema de atividades de “profissões, situações e organizações sociais” (p.19). Segundo o autor, em cada contexto há ciclos identificáveis de textos e de atividades, definidos pelos gêneros característicos de um sistema de atividade. Tal perspectiva é relevante para direcionar o que deve ser observado em uma análise de necessidades que visa identificar os gêneros que circulam em uma determinada prática laboral.

\section{Procedimentos metodológicos}

A pesquisa foi orientada especialmente por aspectos intrínsecos à abordagem qualitativa (CRESWELL, 2010), mas tomando como ponto de partida dados quantitativos apresentados em nível de relevância que surgiram com maior ou menor frequência no corpus.

Realizamos o mapeamento e a interpretação dos enunciados extraídos "de documentos de primeira mão, que não receberam qualquer tratamento analítico" (GIL, 2012, p.51), entre eles: a) Catálogo Nacional de Cursos Técnicos (CNCT) e Catálogo Nacional de Cursos Superiores Tecnológicos (CNCST) - que são as bases para o planejamento de cursos e programas de EPT (BRASIL, 2012) - e; b) ofertas públicas de emprego apresentadas em alguns sites de empresas especializadas em recolocação profissional: www.sine.com.br, www.empregos.com.br, www.catho, www.injobs. Foram analisados anúncios que 
mencionassem o nível técnico e tecnólogo (concluído). Portanto, o levantamento de dados foi de base documental (GIL, 2012).

Para a análise dos dados, foi utilizado o procedimento de codificação e categorização (GIBBS, 2009). Segundo Gibbs (2009, p. 60), “a codificação é uma forma de indexar ou categorizar o texto para estabelecer uma estrutura de ideias temáticas em relação a ele". Por meio da codificação, podemos gerar "índice, temas e categorias" (GIBBS, 2009, p. 60) e, logo, interpretá-los e extrair significados. Sendo assim, foram codificadas e agrupadas, especialmente, as competências em LE requisitadas para/em práticas produtivas/laborais, relacionadas à produção e à compreensão de gêneros textuais do eixo Produção Alimentícia.

\section{Resultados e discussões}

Os resultados apontam na direção do delineamento de aspectos relacionados ao ensino de LE no contexto da Educação Profissional e Tecnológica (EPT), com o estabelecimento das competências em LE necessárias para a produção e recepção dos gêneros textuais que circulam em práticas produtivas de profissionais técnicos e tecnólogos pertencentes a um mesmo eixo tecnológico, atendendo à perspectiva do profissional polivalente. Apresentamos, assim: a) uma proposta de orientação para o estabelecimento de competências; b) um exemplo, utilizando os resultados dos dados levantados nos documentos relacionados ao eixo tecnológico Produção Alimentícia.

\section{A. Proposta de orientação para o estabelecimento de competências}

Se considerarmos que em cada esfera profissional existem gêneros produzidos e/ou recebidos por uma mesma comunidade discursiva, segundo um determinado propósito, então o que buscamos definir em relação ao ensino da LE são as competências (conhecimentos, habilidades, atitudes e valores) em LE necessárias para a inter(ação) em práticas produtivas/laborais recorrentes para essa comunidade, conforme ilustrado no fluxo da Figura 1. 


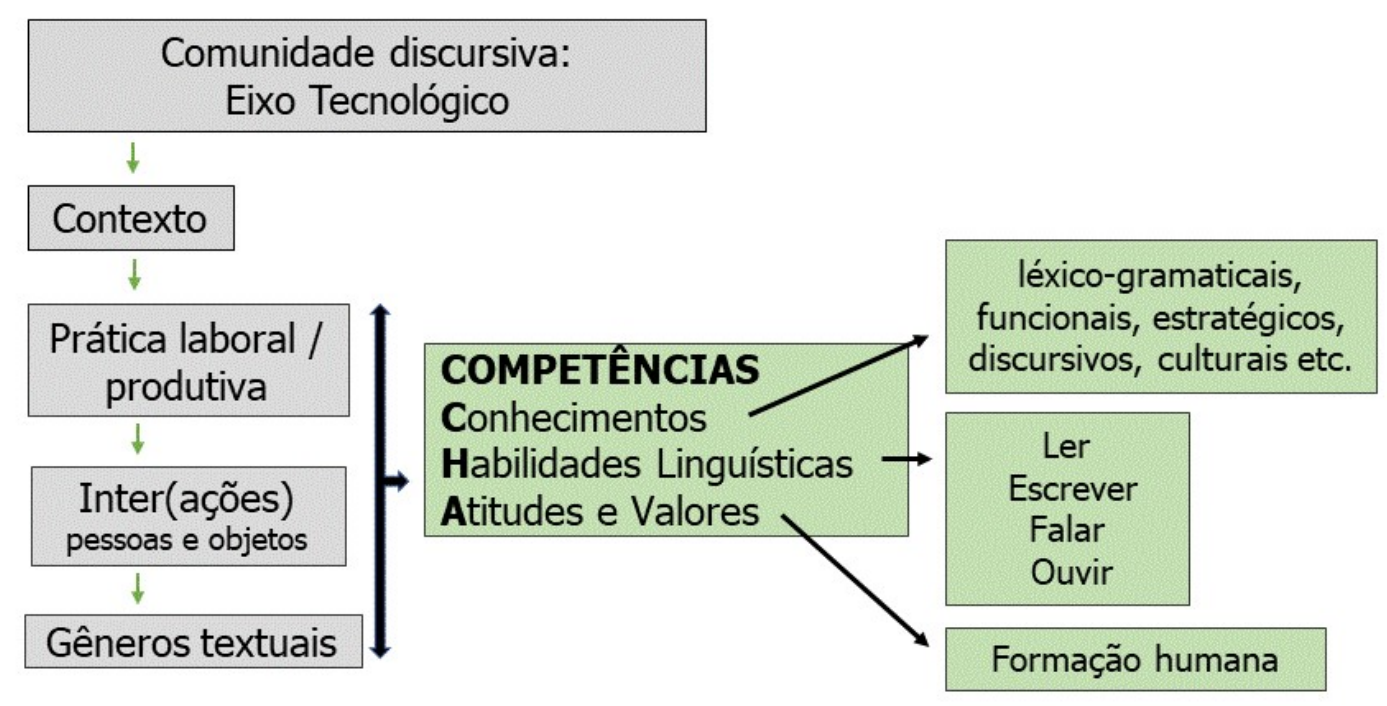

Figura 1. Relação entre comunidade discursiva - práticas laborais - inter(ações) - gêneros - competências. Fonte: a autora.

Cada prática produtiva, que ocorre dentro de uma comunidade discursiva, inclui interações e ações, interagentes e relações sociais. Os interagentes agem e interagem por meio de gêneros textuais. Para essas inter(ações) são necessárias competências em linguagem, isto é, conhecimentos, habilidades e atitudes. Os conhecimentos compreendem os aspectos léxico-gramaticais, funcionais, estratégicos, discursivos etc. As habilidades associam-se, muitas vezes, às quatro habilidades linguísticas (ler, escrever, ouvir e falar). E as atitudes e valores incluem atributos humanos (valores éticos, criatividade, capacidade de trabalhar em equipe, responsabilidade etc.), no atendimento a uma formação humana. 0 desdobramento de competências (conhecimentos, habilidades, atitudes e valores) pode ser visualizado no Q̨uadro 1. 


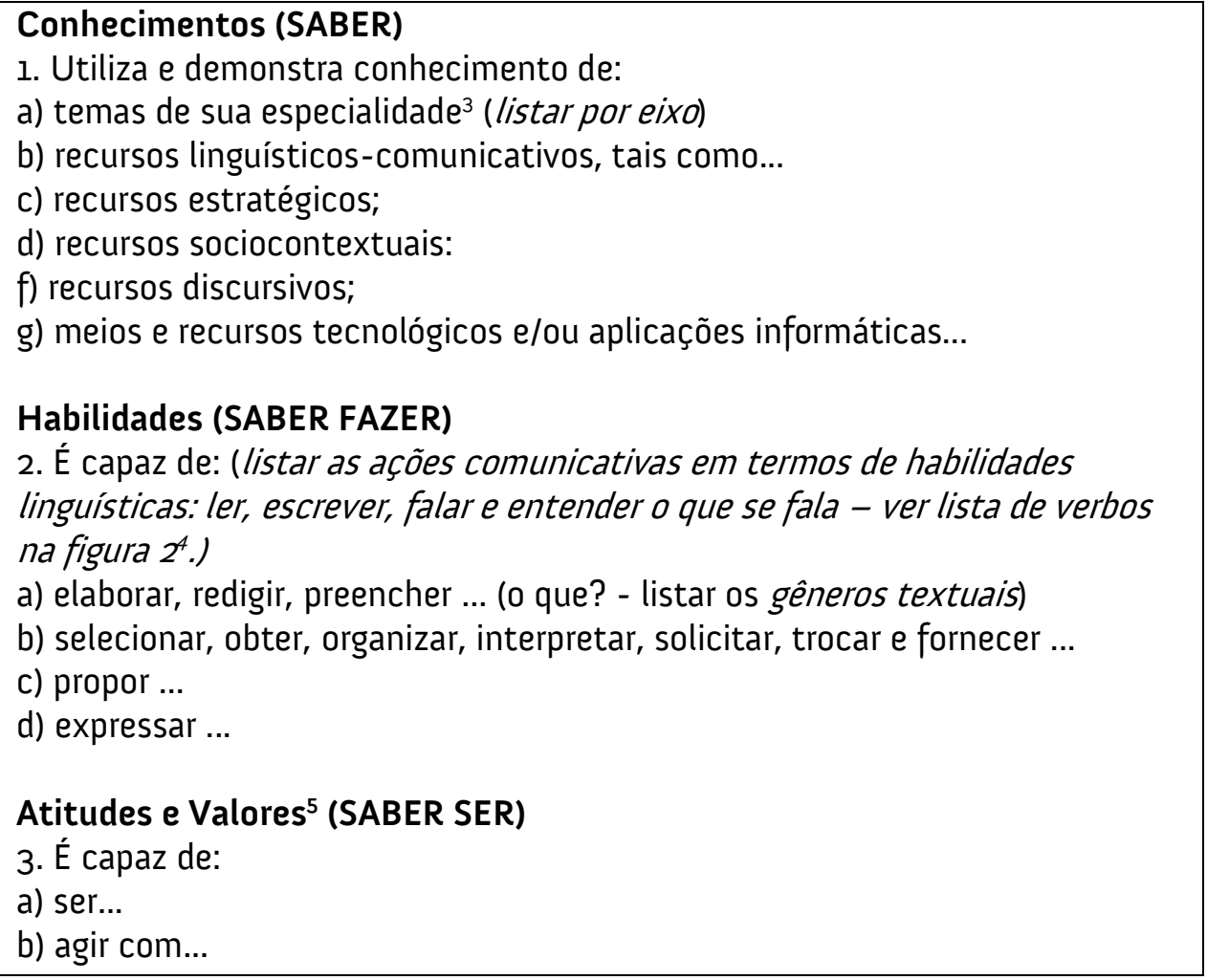

Quadro 1. Desdobramento de competências em LE

Fonte: a autora.

O primeiro elemento considerado na análise dos dados foram as habilidades, por serem essas associadas às ações, que puderam ser localizadas nos catálogos e nas ofertas de emprego, por meio de escolhas lexicais baseadas em sinônimos dos termos de compreensão oral e escrita (ler e ouvir) e dos de produção oral e escrita (falar e escrever). conforme o esquema representado na Figura 2.

\footnotetext{
${ }^{3}$ Conhecimento: possivel encontrar pistas de temas no CNCT 1 e 2, na seção "possibilidades de temas a serem abordados na formação". Ex.: saber legislação. No catálogo 3 do CNCT e nos CNCST é possivel encontrar pistas de temas na descrição do perfil geral do eixo e de cada área.

${ }^{4}$ Habilidades: as ações aparecerão nas ofertas e nos catálogos. Elas podem estar substantivadas, sendo necessário realizar a interpretação em verbos. Será necessário, ainda, associar as ações encontradas a alguma das 4 habilidades linguísticas, conforme exemplo da figura 2 e do quadro 2.

${ }^{5}$ Atitudes e valores: mais facilmente encontrados nas ofertas de emprego. Exemplo: ser pontual, dinâmico.
} 
LER consultar decodificar reconhecer identificar percorrer manusear consultar folhear analisar examinar achar presumir concluir conjecturar pressupor supor traduzir folhear buscar selecionar obter avaliar analisar classificar revisar controlar
ESCREVER redigir preencher completar inscrever transcrever delinear registar editar grafar ortografar citar mencionar notificar referir copiar descrever anotar apontar fichar catalogar listar inventariar apontar relacionar delinear modelar traçar publicar narrar cartear corresponder lavrar alistar assentar consignar exarar inserir filmar gravar insculpir solicitar organizar comunicar propor emitir transmitir especificar controlar cadastrar revisar descrever apresentar exibir formar expor divulgar veicular controlar combinar acordar

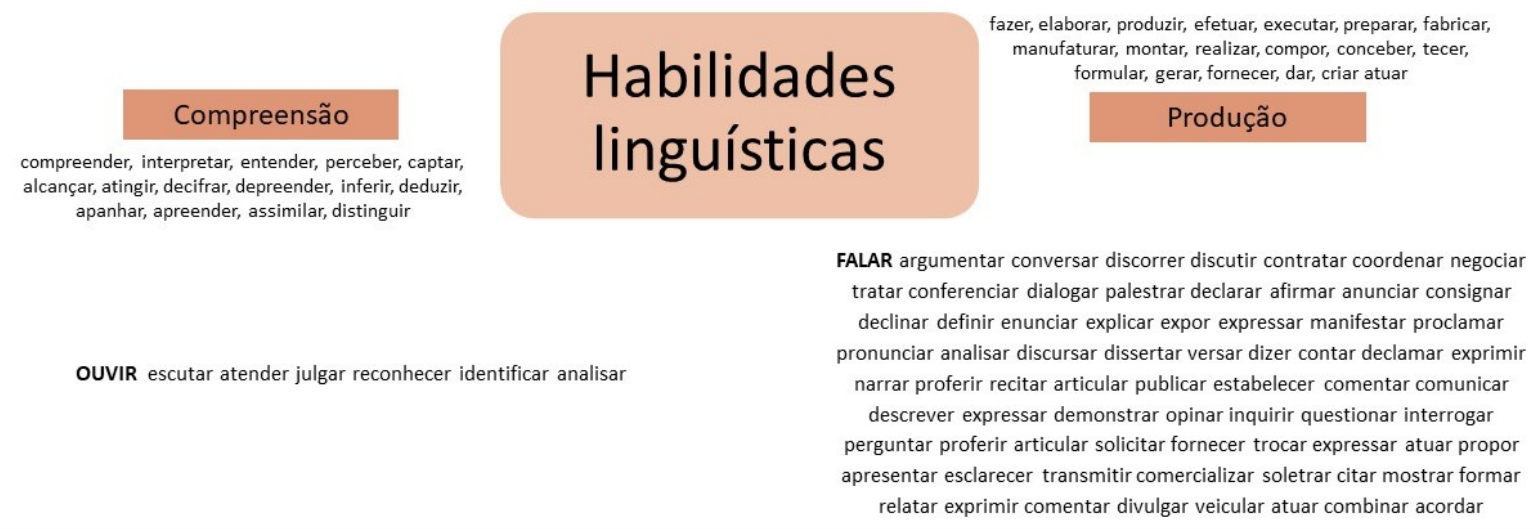

Figura 2. Relação entre ações e habilidades linguísticas.

Fonte: a autora.

Após o levantamento das habilidades e a associação dessas com as ações, foi possível identificar e relacionar para cada ação os diferentes gêneros, de acordo com os diferentes propósitos comunicativos, conforme exemplo (Quadro 2).

A ação, nesse caso, a habilidade de comunicar problemas e propor soluções, faz parte da prática laboral do profissional do eixo Produção Alimentícia. Essa ação pode ser realizada por meio da elaboração de um relatório técnico (habilidade linguística de produção escrita). Para a realização dessa ação, além de conhecimentos de língua e da estrutura, formato, convenções do gênero textual relatório, será necessário mobilizar valores e atitudes como ser claro e técnico. Saber-fazer, que é uma dimensão prática da competência, carece, além de atitude, da mobilização de diferentes valores e atributos humanos. Em caso de um relatório técnico de "não conformidade com padrões alimentícios", por exemplo, o profissional deverá ser capaz de saber lidar com conflitos, entre outras atitudes.

\begin{tabular}{|l|l|}
\hline \multicolumn{1}{|c|}{$\begin{array}{c}\text { Ações I } \\
\text { Habilidades }\end{array}$} & \multicolumn{1}{c|}{ Gêneros } \\
\hline $\begin{array}{l}\text { comunicar } \\
\text { problemas e propor }\end{array}$ & $\begin{array}{l}\text { cadastros, formulários, ficha técnica; } \\
\text { relatórios, pareceres e laudo técnicos-sanitários de produtos da }\end{array}$ \\
\hline
\end{tabular}




\begin{tabular}{|l|l|}
\hline soluções & $\begin{array}{l}\text { indústria alimentícia, de estabelecimento, dos produtos não } \\
\text { conformes - fotos e especificações de não conformidade, de } \\
\text { visitas, de instruções após visitas; } \\
\text { disposições legais; } \\
\text { mensagens eletrônicas. }\end{array}$ \\
\hline
\end{tabular}

Quadro 2. Relação entre habilidades e os gêneros do eixo Produção Alimentícia.

Fonte: a autora.

Com base no exposto, apresentamos um exemplo da proposta com os resultados dos dados relacionados ao eixo tecnológico Produção Alimentícia, com as seguintes especificações:

(1) os elementos comuns à comunidade discursiva: contexto de prática, prática produtiva/laboral, interações e gêneros;

(2) o desdobramento das competências (conhecimentos, habilidades e atitudes) requeridas para as interações dos profissionais técnicos e tecnólogos do eixo;

(3) syllabus - esboço de uma unidade de LE em cursos da EPT pertinentes ao eixo tecnológico mencionado, com base nos elementos e aspectos identificados.

\section{B. Um exemplo da proposta}

1) Elementos comuns à comunidade discursiva

(início)

\begin{tabular}{|c|c|c|}
\hline $\begin{array}{l}\text { Comunidade } \\
\text { discursiva }\end{array}$ & \multicolumn{2}{|c|}{ Eixo Tecnológico Produção Alimentícia: técnicos e tecnólogos } \\
\hline $\begin{array}{l}\text { Contexto de } \\
\text { prática }\end{array}$ & \multicolumn{2}{|c|}{$\begin{array}{l}\text { Agroindústria e indústrias de alimentos; laboratório e instituições de } \\
\text { controle de qualidade; estabelecimentos de comercialização de produtos } \\
\text { específicos; empreendimento próprio. }\end{array}$} \\
\hline $\begin{array}{l}\text { Prática } \\
\text { laboral }\end{array}$ & \multicolumn{2}{|c|}{$\begin{array}{l}\text { Situações de assessoria e consultoria científica, legal ou técnica; } \\
\text { auditorias; inspeções; vistorias; segurança de procedimentos e outros. }\end{array}$} \\
\hline \multirow[t]{2}{*}{ Interação } & Pessoas & Objetos \\
\hline & $\begin{array}{l}\text { operadores de } \\
\text { fornecedores, clientes, } \begin{array}{l}\text { produção, } \\
\text { gestores, } \\
\text { colaboradores, } \\
\text { engenheiros. }\end{array}\end{array}$ & $\begin{array}{l}\text { maquinários, ferramentas, } \\
\text { equipamentos, produtos, insumos, } \\
\text { programas e softwares. }\end{array}$ \\
\hline
\end{tabular}




\begin{tabular}{l|l}
\hline Gêneros & informes (em relação a produtos alimentícios); relatórios (técnicos- \\
Textuais & sanitários de produtos da indústria alimentícia; de estabelecimento; dos \\
& produtos não conformes - fotos e especificações de não conformidade; de \\
& visitas; de instruções após visitas; diários; de acompanhamento das \\
& demandas de clientes); gráficos e demonstrativos em geral; questionários; \\
& pesquisa de satisfação; mensagens eletrônicas; planilhas; cadastros; fichas \\
& técnicas; formulários; fluxogramas; disposições legais do âmbito \\
alimentário; normas e procedimentos de segurança alimentar; planos de \\
ações
\end{tabular}

Quadro 3. Elementos comuns à comunidade discursiva

Fonte: a autora.

2) Competências (conhecimentos, habilidades, atitudes e valores) requisitadas nas práticas produtivas mapeadas

(início)

\section{COMPETÊNCIA}

\section{Conhecimentos}

1. Utiliza e demonstra conhecimento de:

a) legislação vigente de alimentos; normas técnicas de segurança alimentar e qualidade;

b) léxico especializado do eixo de Produção Alimentícia;

c) recursos discursivos como manter, controlar, tomar e/ou ceder o turno de fala; coesão e coerência textual etc.;

g) meios e recursos tecnológicos e/ou aplicações informáticas, como por exemplo: internet, programas para edição de texto entre outros.

\section{Habilidades}

2. É capaz de:

a) elaborar, redigir e/ou preencher informes e relatórios técnicos-sanitários de produtos da indústria alimentícia e de estabelecimento e serviços relacionados com a alimentação; gráficos e demonstrativos em geral; questionários alimentares; pesquisa de satisfação; mensagens eletrônicas, planilhas, cadastros, fichas técnicas, formulários;

b) buscar, selecionar, obter, organizar, interpretar, avaliar, solicitar, trocar e fornecer informações de diversas fontes, dados, questionário, cálculos; fluxogramas, informações 


\section{LínguaTec}

estatísticas; relatórios; informes em relação a produtos alimentícios; disposições legais do âmbito alimentário;

c) expressar condições, prazos, alternativas, possibilidades, necessidades;

d) transmitir informação, ideias, procedimentos;

e) comunicar problemas e soluções, de maneira clara oralmente e por escrito, a um público especializado ou não do contexto de produção alimentícia;

f) realizar assessoria e consultoria científica, legal ou técnica;

g) atuar com auditorias, inspeções, vistorias, segurança de procedimentos e outros;

h) comercializar e distribuir produtos;

i) ler e produzir textos técnicos;

j) elaborar e analisar os relatórios dos produtos não conformes (fotos e especificações de não conformidade) para evidenciar a devolução aos fornecedores;

k) elaborar normas e procedimentos de segurança alimentar;

l) elaborar relatórios de visitas, diários e de acompanhamento das demandas de clientes;

m) elaborar planos de ações;

n) analisar, classificar e controlar documentos;

o) gerar relatório de instruções após visitas;

p) propor soluções;

q) expressar conhecimento técnico

r) expressar acordo ou desacordo, condições e prazos, alternativas e possibilidades, etc.

\section{Atitudes e valores}

3. É capaz de:

a) demonstrar empatia;

b) apresentar capacidade de organização e iniciativa;

c) agir proativamente;

d) apresentar relacionamento interpessoal e positivo para trabalhar em equipe; 
e) comunicar-se de forma clara, objetiva e precisa;

f) fazer anotações enquanto ouve;

g) demonstrar atenção aos outros em sua postura corporal;

h) esclarecer dúvidas;

i) permitir interação entre as partes;

j) buscar pela excelência;

k) demonstrar agilidade no atendimento;

l) estar preparado para dar informações adequadas;

m) ter paciência ao tratar com clientes;

n) demonstrar boa comunicação e facilidade em lidar com público;

o) saber lidar com conflitos;

p) ter facilidade de trabalho com equipe;

q) saber trabalhar sob pressão;

r) ser dinâmico.

3) Syllabus

(início)

\begin{tabular}{|c|c|c|c|c|c|}
\hline Tema & $\begin{array}{l}\text { Prática } \\
\text { Laboral }\end{array}$ & $\begin{array}{l}\text { Ações e funções } \\
\text { comunicativas e } \\
\text { profissionais }\end{array}$ & $\begin{array}{l}\text { Gêneros } \\
\text { Textuais }\end{array}$ & $\begin{array}{l}\text { Elementos } \\
\text { linguísticos- } \\
\text { comunicativos, } \\
\text { lexicais e } \\
\text { discursivos }\end{array}$ & $\begin{array}{l}\text { Cultura } \\
\text { Cidadania }\end{array}$ \\
\hline $\begin{array}{l}\text { Controle } \\
\text { de } \\
\text { qualidade: } \\
\text { em um } \\
\text { fábrica/ } \\
\text { indústria }\end{array}$ & $\begin{array}{l}\text { Vistoria } \\
\text { e } \\
\text { inspeção }\end{array}$ & $\begin{array}{l}\text {-Vistoriar a } \\
\text { qualidade do } \\
\text { produto } \\
\text { alimentício } \\
\text {-Mostrar } \\
\text { (in)conformidade. }\end{array}$ & $\begin{array}{l}\text { cadastro, } \\
\text { ficha técnica, } \\
\text { formulários, } \\
\text { laudo, parecer } \\
\text { e relatório } \\
\text { técnico de } \\
\text { defeitos, de } \\
\text { desvios de }\end{array}$ & $\begin{array}{l}\text { verbos e } \\
\text { expressões de } \\
\text { obrigação e } \\
\text { necessidade: } \\
\text { tener que/deber } \\
\text { que/haber que, } \\
\text { condicional de } \\
\text { modéstia: "yo }\end{array}$ & $\begin{array}{l}\text { Sustentabilidade } \\
\text { na indústria. } \\
\text { Ser claro e } \\
\text { técnico ao } \\
\text { relatar um } \\
\text { problema. }\end{array}$ \\
\hline
\end{tabular}




\begin{tabular}{|c|c|c|c|c|c|}
\hline & & $\begin{array}{l}\text {-Comunicar } \\
\text { advertir } \\
\text { problemas. } \\
\text {-Sugerir } \\
\text { melhorias } \\
\text { produção. } \\
\text {-Expressar, } \\
\text { condições } \\
\text { prazos, } \\
\text { alternativas } \\
\text { possibilidades, } \\
\text { etc. }\end{array}$ & $\begin{array}{l}\text { qualidade, dos } \\
\text { testes } \\
\text { realizados, } \\
\text { fotos e } \\
\text { especificações } \\
\text { de não } \\
\text { conformidade, } \\
\text { instruções } \\
\text { após visitas. }\end{array}$ & $\begin{array}{l}\text { diría que eso no } \\
\text { era asi"; } \\
\text { imperativo; } \\
\text { enunciado } \\
\text { declarativo }+ \\
\text { consequência; } \\
\text { recomendação: } \\
\text { sería } \\
\text { aconsejable... } \\
\text { para evitar... } \\
\text { como medida } \\
\text { de...; numerais, } \\
\text { pesos e } \\
\text { medidas, verbos } \\
\text { relacionados ao } \\
\text { processo de } \\
\text { fabricação de } \\
\text { alimentos; } \\
\text { adjetivos; } \\
\text { superlativo e } \\
\text { comparativo, } \\
\text { interrogativos, } \\
\text { léxico } \\
\text { específico; } \\
\text { normas } \\
\text { técnicas, } \\
\text { abreviaturas; } \\
\text { estrutura, } \\
\text { formato } \\
\text { convenções dos } \\
\text { textos técnicos. }\end{array}$ & $\begin{array}{l}\text { Julgar } \\
\text { criticamente. }\end{array}$ \\
\hline
\end{tabular}

Q̨uadro 5. Syllabus de uma unidade

Fonte: a autora.

Apesar de as competências estarem vinculadas, a título de exemplo, ao eixo tecnológico mencionado, entendemos que as orientações discutidas anteriormente e o modelo de desdobramento de competênciapoderiam ser aplicados para os demais eixos tecnológicos 


\section{Considerações finais}

Neste trabalho, apresentamos uma proposta de orientação para a elaboração de aspectos relacionados ao ensino da LE na EPT com base na teoria da análise de necessidades e da teoria de gêneros. 0 procedimento de análise de necessidades baseado em gêneros representa um passo importante para a organização curricular da LE na EPT, uma vez que os resultados apontaram para o delineamento do desenvolvimento das competências (proposta formativa prescrita e almejada nos documentos que orientam a organização dos cursos da EPT) necessárias para a produção de gêneros textuais específicos de determinada comunidade discursiva, nesse caso, do eixo tecnológico Produção Alimentícia.

Foram consideradas as práticas comuns aos profissionais (técnicos e tecnólogos) do referido eixo tecnológico, vislumbrando a construção de itinerários formativos flexíveis, diversificados e atualizados em linguagem específica dessa comunidade discursiva, com a possibilidade de adaptações para cada habilitação profissional e para cursos de diferentes níveis e modalidades de ensino.

No tocante ao ensino desse jargão lexical específico de um eixo, este trabalho não teve como objetivo apresentar os gêneros como modelos fixos a serem imitados pelos alunos, mas familiarizá-los com os gêneros que circulam nessa comunidade, levá-los a refletir sobre por que determinado texto é apropriado em dado contexto profissional, a refletir sobre as situações comunicativas em que um gênero pode ser utilizado, pensando em sua área profissional, bem como levá-los a usarem os gêneros para compreender e deduzir as inter(ações) de sua área profissional e a construir seus próprios textos; podendo, assim, desenvolver competências em linguagem contextualizadas e de acordo com suas necessidades, como parte de sua preparação acadêmica para o mundo do trabalho.

\section{Referências}

AGUIRRE BELTRÁN, B. Aprendizaje y enseñanza con fines específicos: comunicación en ámbitos académicos y profesionales. Madrid: SGLE, 2012.

AUGUSTO-NAVARRO, E. H. Necessidades e Interesses Contemporâneos no EnsinoAprendizagem de Inglês para Propósitos Específicos. In: SILVA, K. A; ALVAREZ, M. L. O. Perspectivas de Investigação em LA. Campinas: Pontes, 2008. 
BAZERMAN, C. Gêneros textuais, tipificação e interação. São Paulo: Cortez, 2005.

BRASIL. Ministério da Educação. Conselho Nacional de Educação. Parecer CNE/CEB $n^{\circ}$ 16/99, aprovado em 05 de outubro de 1999. Diretrizes curriculares nacionais para a Educação Profissional de Nível Técnico. 1999.

CRESWELL, J. W. Projetos de pesquisa: métodos qualitativo, quantitativo e misto. Tradução Magda Lopes. 3 ed. Porto Alegre: Artmed, 2010.

DUDLEY-EVANS, T; ST. JOHN, M. J. Developments in English for Specific Purposes: a multidisciplinary approach. Cambridge: Cambridge University Press, 1998.

GIBBS, G. Análise de dados qualitativos. Coleção pesquisa qualitativa/coordenada por Uve Flick. Porto Alegre: Artmed, 2009.

GIL, A. C. Métodos e técnicas de pesquisa social. 6 ed. São Paulo: Atlas, 2012.

HUTCHINSON, T.; WATERS, A. English for specific purposes: a learning-centered approach. Cambridge: Cambridge University Press, 1987.

MARCUSCHI, L. A. Apresentação. In: Barzerman, C. Gêneros, tipificação e interação. São Paulo: Cortez, 2005.

PERRENOUD, P. Construir competências desde a escola. Porto Alegre: Artes Médicas Sul, 1999.

RAMOS, A. A. L. Um caminho estrangeiro na compreensão do gênero: estratégias cognitivas em produção textual do CELPE-Bras. 2007. 240 f. Tese (Doutorado em Linguística) Universidade de Brasília, Brasília, 2007.

RAMOS, R. C. G. Instrumental no Brasil: a desconstrução de mitos e a construção do futuro. In FREIRE, M; VIEIRA-ABRAHÃO, M. H.; BARCELOS, A. M. F. (Org.). Linguística Aplicada e Contemporaneidade. Campinas, SP: Pontes, 2005.

. Gêneros textuais: uma proposta de aplicação em cursos de inglês para fins especificos. The ESPecialist, v. 25, n. 2, p. 107-129, 2004.

LIMA-LOPES, R. E.; GAZOTTI-VALLIM, M. A. Análise de necessidades: identificando gêneros acadêmicos em um curso de leitura instrumental. The ESPecialist, São Paulo, v. 25, n. 1, p. 1-29, 2004.

SWALES, J. M. Genre Analysis: English in academic and research settings. Cambridge: Cambridge University Press, 1990.

Data de submissão: 30/09/2018. Data de aprovação: 14/11/2018. 